\title{
Optical and spectral characteristics of low pressure air discharges as sprite models
}

\author{
Y. Goto ${ }^{1}$, Y. Ohba ${ }^{1}$ and K. Narita ${ }^{2}$ \\ ${ }^{1}$ Department of Electrical Engineering, Tohoku Gakuin University, \\ 1-13-1, Chuo, Tagajo, Miyagi, 985-8537, Japan \\ ${ }^{2}$ Miyagi Polytechnic Center
}

\begin{abstract}
The experiments for the optical and spectral characteristics of the long gap air discharges under low pressure as the model of red sprite or blue jet have been reported. The results are compared with the characteristics of sprites. The experimental air pressure have been varied from $7.5 \mathrm{~m}$ Torr to $20 \mathrm{Torr}$, corresponding to the altitude of $80 \mathrm{~km}$ and $25 \mathrm{~km}$, respectively. Using the band path filter which cut-off wave length is $500 \mathrm{~nm}$, the relationship of between whole light flux in the range of $500 \mathrm{~nm}$ and $800 \mathrm{~nm}$ and the air pressure has been studied. The highest light flux intensity occurs at about $80 \mathrm{mT}$ Torr which corresponds to the altitude of $65-67 \mathrm{~km}$.
\end{abstract}

Keyword: long gap air discharge, spectroscopic measurement, red sprite, blue jet

\section{Introduction}

In the middle atmosphere region, the large optical transient phenomena, associated with lightning discharge, have been studied with an intensity (Vaughan and Vonnegut, 1989; Franz et al., 1990; Sentman and Wescott, 1993; Lyons, 1994; William et al., 1995; Boccippio et al., 1995; Hampton et al., 1996; Dowden et al., 1996; Lyons, 1996; Pasko et al., 1997; Hardman et al., 2000; Barington-Leigh et al., 2001; Wescott et al., 2001; Hayakawa et al.,2006). Above phenomena have been classified into a red sprite (Sentman et al.,1995) and a blue jet (Wescott et al., 1995). The red sprite has a duration of less than $17 \mathrm{~ms}$ and their vertical span is the distance from altitude of $40 \mathrm{~km}$ to $90 \mathrm{~km}$ (the air pressure changes from 2.15Torr to $1.4 \mathrm{mTorr}$ ). The blue jet has been narrow and upward directed cone of blue light emanating directly from the top of active thunderstorm system and propagates upward to the altitude of $40 \mathrm{~km}$ (Sentman et al., 1996).

They are very important themes to clarify the characteristics of those discharges and to investigate the interference of a sprite and a jet phenomena with aerospace activities in the $20-100 \mathrm{~km}$ layer, including research balloons, military aviation, the next generation high speed civil transport and Space Shuttle.

In order to investigate air breakdown characteristics in the uniform electric field at the air pressure corresponding to middle atmospheric discharges above thunderstorm systems, air breakdown voltages for D.C. voltage and switching impulse at low pressure and long gap had been measured in the high voltage laboratory of Tohoku Gakuin University (Goto et al., 2003).

In this paper, the optical and spectral characteristics of the long gap low pressure air discharges are reported and the results are compared with the models of red sprites and blue jets.

\section{Apparatus and procedure}

The block diagram of experimental apparatus is shown in Figure 1. The high voltage electrode is the large aluminum disk having the rounded edge, and its diameter is $3.2 \mathrm{~m}$. This electrode is suspended by an insulator above a grounded aluminum plate. Both electrodes are formed a parallel plane gap, and a discharge tube is arranged along the axis of both disk electrodes. The discharge tube is made with a Pyrex glass, its length is $1.5 \mathrm{~m}$ and outer diameter is $0.15 \mathrm{~m}$. This tube is exhausted by an oil rotary vacuum pump, and a low pressure is made to get air into through a leak valve. A dry air is achieved through a desiccator. Mixing ratios of atmospheric constituent are almost constant below the altitude of $80 \mathrm{~km}$. 


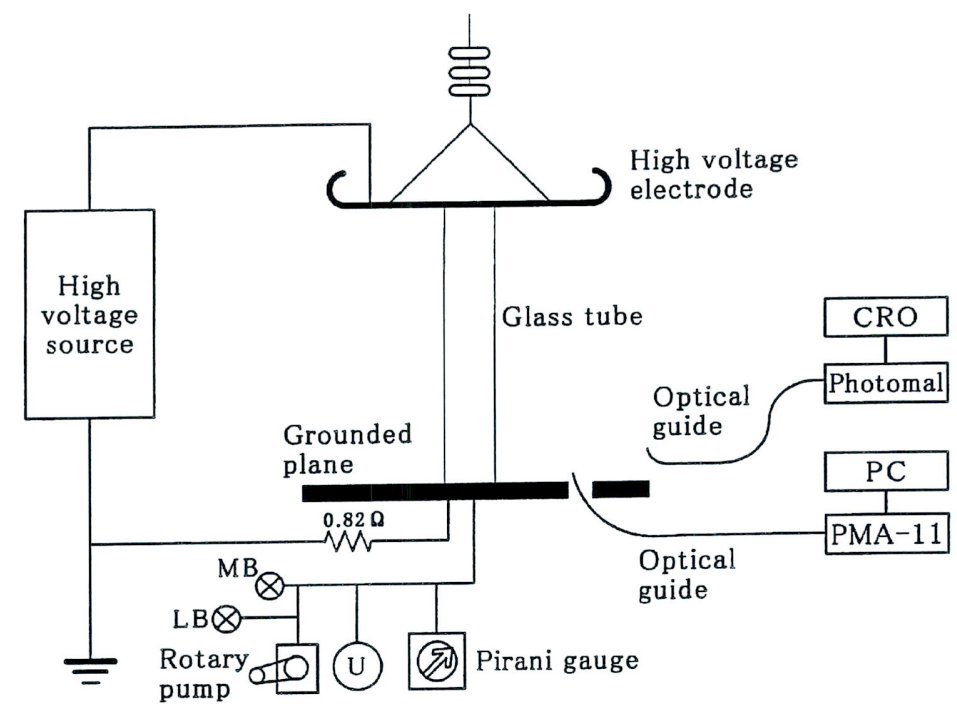

Fig. 1 The block diagram of the experimental apparatus

Applied D.C. voltage were $50 \mathrm{kV}(\mathrm{C}=2.2 \mu \mathrm{F}, \mathrm{W}=2.75 \mathrm{~kJ})$ and $100 \mathrm{kV}(\mathrm{C}=0.12 \mu \mathrm{F}, \mathrm{W}=0.6 \mathrm{~kJ})$, and the corresponding current limiting resistances were used $1.5 \mathrm{k} \Omega$ and $3.0 \mathrm{k} \Omega$ respectively. The discharge current waveform was measured with a digital oscilloscope (Tektronix TDS220) via a shunt resistance of $0.82 \Omega$. The total light waveform was simultaneously observed by a side-on type photo-multiplier (RCA R928) with a total flux sensor.

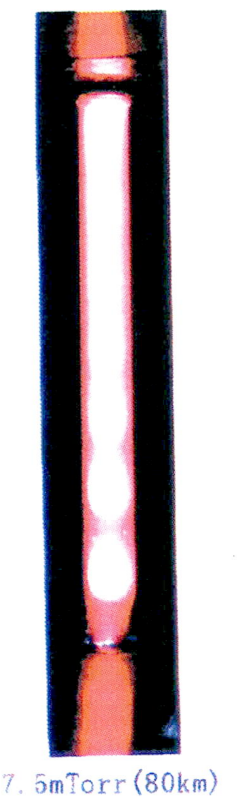

a)

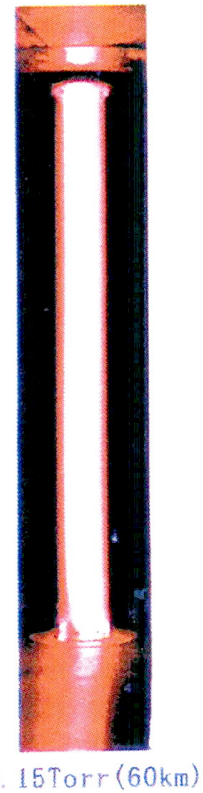

b)

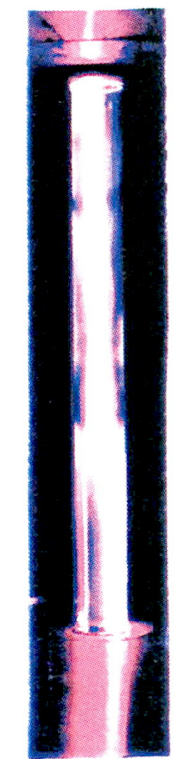

2. 0 Torr $(40 \mathrm{~km})$

c)

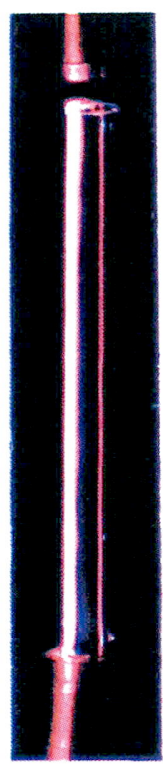

7. $0 \operatorname{Torr}(31 \mathrm{~km})$

d)

Fig. 2 Pictures of low pressure air discharges 
The colors and the states of the optical emissions in the low pressure air discharges have been observed with a still camera. The pressure dependence of the spectral distribution from the discharges have been measured with the optical spectrum analyzer (Hamamatsu Photonics, Photonic Multichannel Analyzer PMA 11). Its detectable light wave length is ranged from $300 \mathrm{~nm}$ to $800 \mathrm{~nm}$. The band path filter which cut-off wave length is $500 \mathrm{~nm}$, has been used, because that to clarify the characteristics for the long wave region of these discharge emission as the sprite model.

For avoiding the influence of charge around discharge tube, the electric charge up of the inside and outside wall of the tube was removed every discharge.
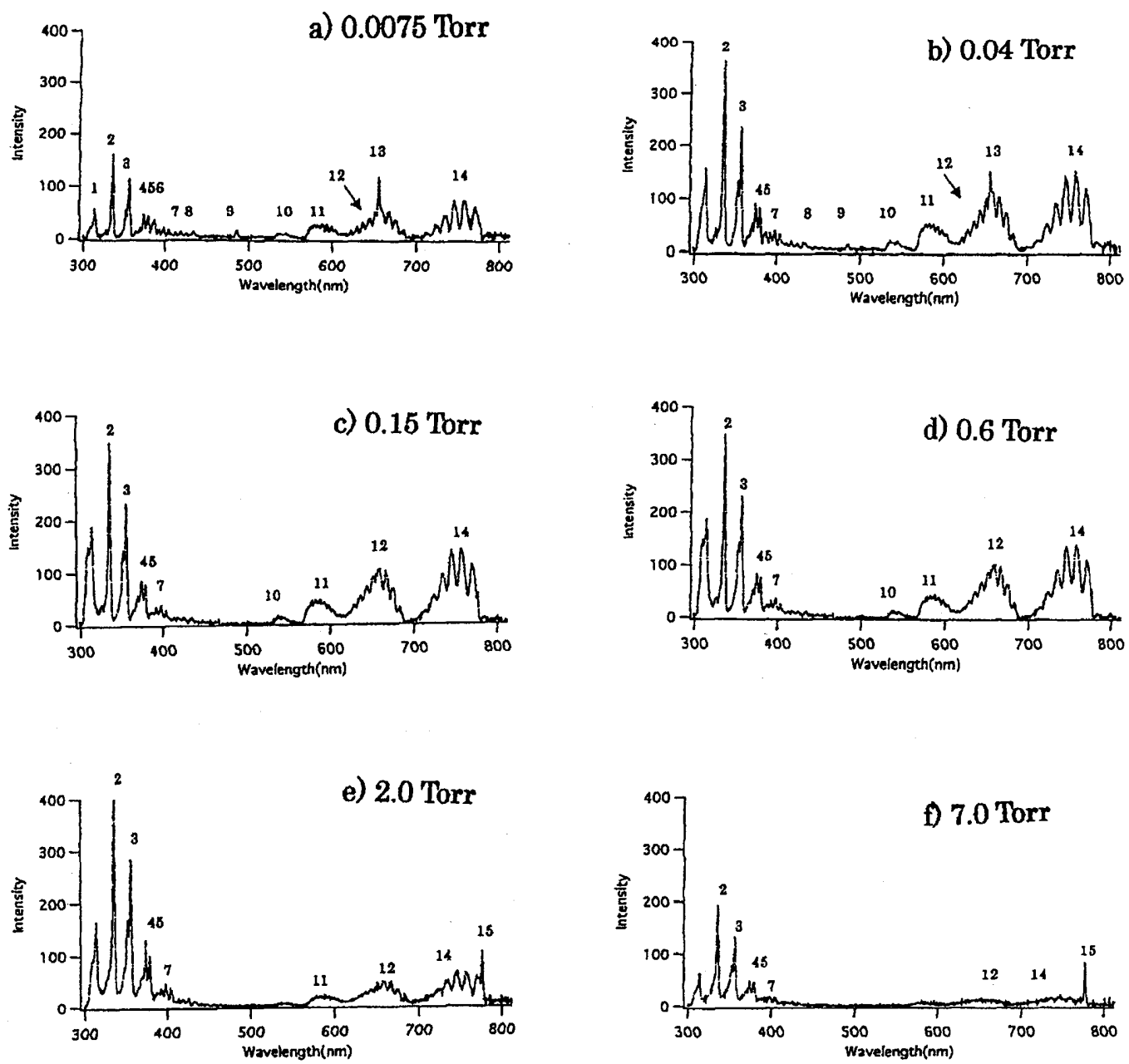

Wave length: $1 . \mathrm{N}_{2} 313.6 \mathrm{~nm}, 2 . \mathrm{NII} 333.0 \mathrm{~nm}, 3.0$ II $354.5 \mathrm{~nm}, 4.0$ II $372.7 \mathrm{~nm}$, 5.0 I $377.7 \mathrm{~nm}, 7 . \mathrm{N}_{2} 399.8 \mathrm{~nm}, 11 . \mathrm{N}_{2}$ band head, $12 . \mathrm{N}_{2}$ band head, $13 . \mathrm{H}_{\alpha} 656.2 \mathrm{~nm}, 14 . \mathrm{N}_{2}$ band head, 15.0 I $777.6 \mathrm{~nm}$

Fig. 3 The obtained pressure dependence of spectral distributions 


\section{Experimental results and discussions}

\subsection{Optical and spectral observation results for low pressure air discharges}

As the observed results, the colors and states in the low pressure air discharges with $1.5 \mathrm{~m}$ glass tube by a still camera are purple red and glow type like as the red sprite in low pressure range as shown in Figure 2 a) and b), purple blue and streamer type like as the blue jet in higher pressure range as shown in Figure $2 \mathrm{c}$ ) and d).

Those colors and states may be change with both the air pressure and the discharge current. Therefore, the spectroscopic distributions of the light emission in the low pressure air discharge have been measured. The obtained pressure dependence of spectral distribution are shown in Figure 3(a) (f) for each air pressure respectively.

The obtained spectra in the low pressure air discharges as the model for sprite discharges are similar to the observed spectra of natural sprite in the wave length range between $550 \mathrm{~nm}$ and $800 \mathrm{~nm}$ and those correspond to $\mathrm{N}_{2}(\mathrm{~A}-\mathrm{B})$ and $\mathrm{N}_{2}{ }^{+}(\mathrm{A}-\mathrm{B})$ emission.

Considering the pressure dependence of spectral distribution, the intensity of $\mathrm{H}_{\alpha}$ line $(656.2 \mathrm{~nm}$, No.13 in Fig. 3) decreases with increasing air pressure, while the intensity of OI line (777.6nm, No.15 in Fig. 3) increases with the air pressure.

The emission intensity of red range is the highest at $40 \mathrm{~m}$ Torr (about $70 \mathrm{~km}$ equivalent altitude) shown in Figure 3. The spectral line intensity of OII and NII increase and the color of the discharges tend to blue-purple.

The synthetic spectra of $\mathrm{N}_{2}$ and $\mathrm{N}_{2}{ }^{+}$emission are shown in Figure 4 (Green et al., 1996, Heavner et al., 1996, Hampton et al., 1996).

An example of spectral distributions from the dry air and normal room air discharges are shown in Figure 5 a) and b), respectively. Both spectral distributions are same. So it is confirmed that there is no influence of air humidity for the spectral characteristics of low pressure air discharges.

\subsection{Pressure dependence of total} light intensity as sprite model discharges

To clarify the characteristics of sprite discharges, the band pass filters with $500 \mathrm{~nm}$ cutoff wave length have been set at the input of the light guides. The filtered spectral distribution, the filtered total light intensity wave form and the discharge current wave form have been measured simultaneously at various air pressure between

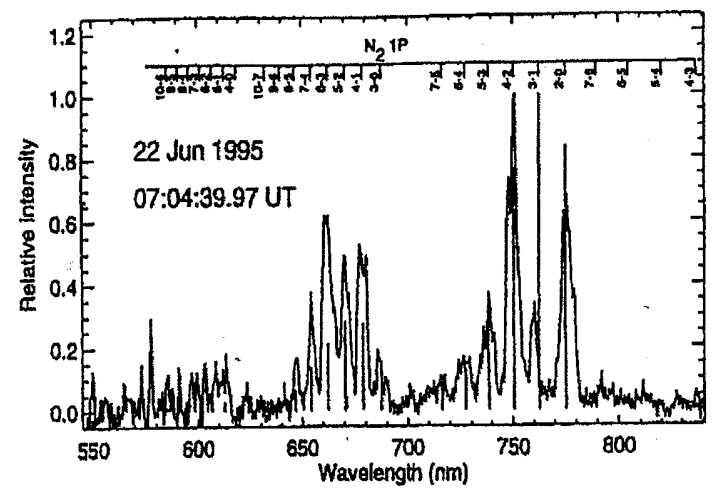

a) spectral distribution from the natural sprite

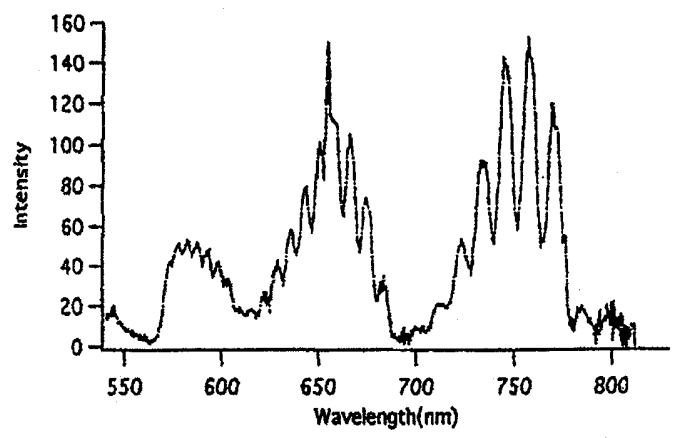

b) spectral distribution obtained by this study

Fig. 4 Comparison of synthetic spectra of $\mathrm{N}_{2}(\mathrm{~B}-\mathrm{A})$ and $\mathrm{N}^{+}$ (A-X) 
7.5mTorr and 0.6Torr. The filtered total light intensity wave form which measured with a photo-multiplier R-928 is shown in Figure 6 with the discharge current. The filtered spectral distribution measured with optical spectrum analyzer is shown in Figure 7.

From the obtained spectral distributions and the total light intensity wave forms, total spectral flux $\mathrm{S}$ integrated by the spectral distributions and integrated total light intensity $T$ as the time integral of the total light wave form are calculated for each air pressure. These dependence for air pressure are shown in Table 1.

From Table 1, it is clear that $\mathrm{S}$ is proportional to $T$. In the air pressure range between $7.5 \mathrm{mT}$ Torr and 0.08 Torr, $S$ and $T$ increase larger and larger with air pressure and then they decrease with air pressure. As the result, the total light intensity is the highest in the range of air pressure between 0.04 Torr(corresponds to $70 \mathrm{~km}$ ) and 0.08 Torr $(65 \mathrm{~km})$.

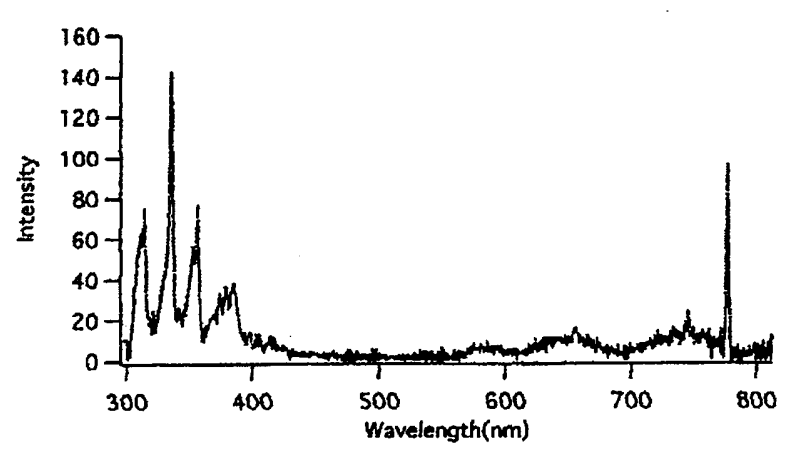

\section{a) spectral distribution at dry air}

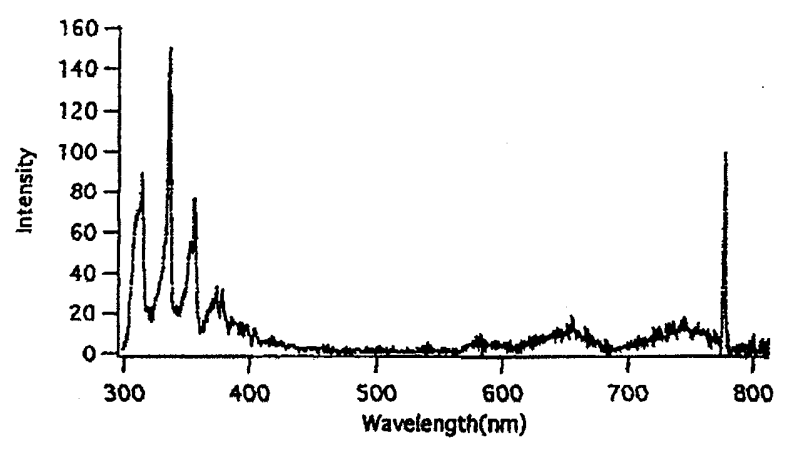

b) spectral distribution at room air

Fig. 5 The influence of humidity to spectral distribution (7Torr)

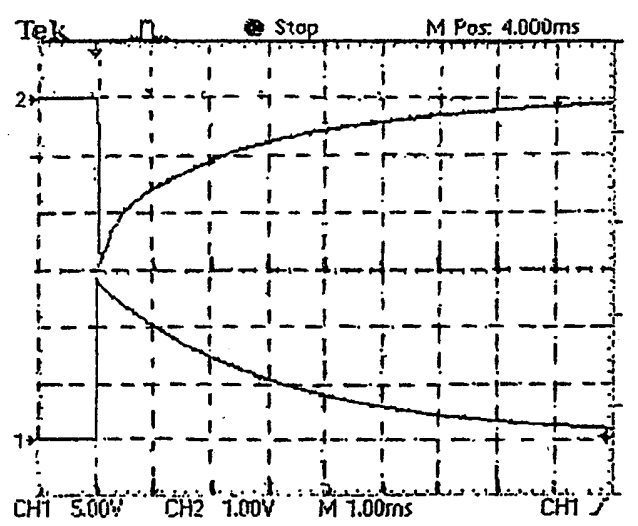

\section{Integrated total light intensity}

$T=54$

Upper: light intensity waveform

Lower: discharge current waveform

Fig. 6 Total light intensity waveform and discharge current waveform at 0.08 Torr 
Table 1 The air pressure dependence of total spectral flux S and total light intensity $\mathrm{T}$

\begin{tabular}{lcrr}
\hline Air pressure [Torr] & Equivalent altitude $[\mathrm{km}]$ & $\mathrm{S}$ & $\mathrm{T}$ \\
\hline & & 72 & 14 \\
0.0075 & 80 & 180 & 36 \\
0.02 & 75 & 253 & 48 \\
0.04 & 70 & 281 & 54 \\
0.08 & 65 & 238 & 44 \\
0.15 & 60 & 161 & 32 \\
0.3 & 55 & 150 & 28 \\
0.6 & 50 & & \\
\hline
\end{tabular}

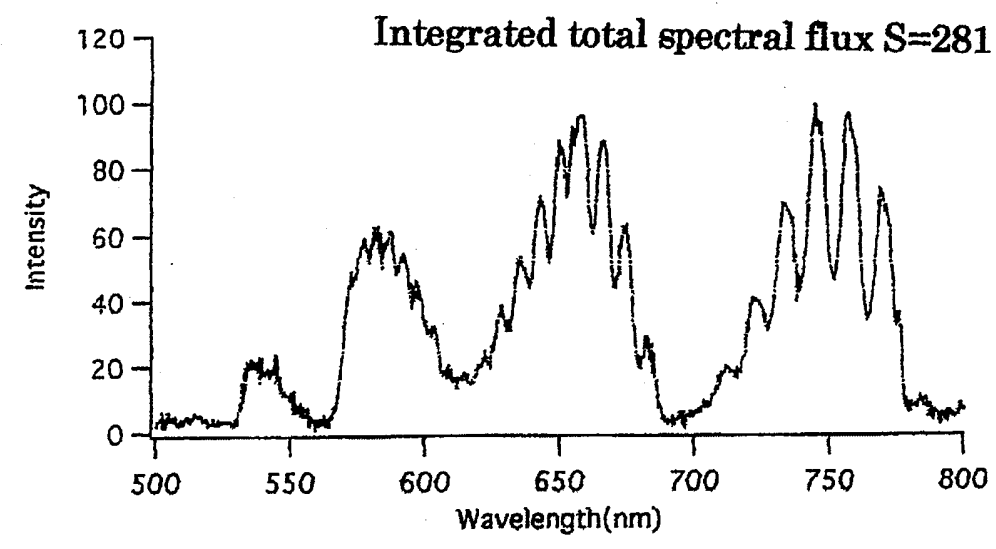

Fig. 7 The spectral distribution at 0.08 Torr

3.3 The relation of the peak value of total light intensity and the crest value of discharge current

Table 2 shows the relation of the peak value $\mathrm{Y}$ measured by photo-multiplier and maximum discharge current $\mathrm{X}$ at the air pressure $0.04 \mathrm{~m}$ Torr (corresponds to about $70 \mathrm{~km}$ ). These $\mathrm{X}$ and $\mathrm{Y}$ are correlated as following equation :

$$
Y=59.3 \times X
$$

This relationship shows that the total light intensity of natural sprites is proportional to sprite discharge current.

Table 2 The relationship of the crest value $X$ of current and the total light intensity $\mathrm{Y}$ at air pressure 0.04 Torr

\begin{tabular}{rr}
\hline $\mathrm{X}[\mathrm{A}]$ & $\mathrm{Y}[\mathrm{mV}]$ \\
\hline & \\
\hline .4 & 180 \\
18.5 & 500 \\
33.0 & 1100 \\
& 2000 \\
\hline
\end{tabular}




\section{Conclusion}

The conclusions of this study for the low pressure long gap air discharges, are as follows:

(1) The colors, profiles and spectral distributions depend on the air pressure.

(2) The optical spectra of this experiments are quite similar to the observed spectra of natural sprite in wave length range between $500 \mathrm{~nm}$ and $800 \mathrm{~nm}$. So, the present experiments could be reasonable to the sprite model experiments.

(3) The spectral distributions are not influenced by air humidity.

(4) The total spectral flux S integrated by the spectral distribution is proportional to the integrated total light intensity $\mathrm{T}$ as the time integral of the total light wave form. Therefore, the total light intensity is the highest at the air pressure in the range from 0.04 Torr (corresponds to $70 \mathrm{~km}$ height) to 0.08 Torr $(65 \mathrm{~km})$.

(5) The peak value of total light intensity is proportional to the crest value of discharge current.

\section{References}

Barrington-Leigh, C. P., U. S. Inan, and M. Stanley, Identification of sprites and elves with intensified video and broadband array photometry, J. Geophys. Res., 106, 1741-1750, 2001.

Boccippio, D. J., E. R. Williams, S. J. Heckman, W. A. Lyon, I. T. Baker, and R. Boldi, Sprites, ELF Transients, and Positive Ground Strokes, Science, 269, 1088-1091, 1995.

Dowden, R.L., and J. B. Brundell, Are VLF rapid onset, rapid decay perturbations produced by scattering off sprite plasma?, J. Geophys. Res.,101, 19,175-19,183, 1996.

Franz, R. C., R. J. Nemzek, J. R. Winckler, Television Image of a Large Upward Electrical Discharge Above a Thunderstorm System, Science, 249, 48-51, 1990.

Goto, Y., Y. Sato, Y. Ohba, The optical and spectral measurements of low pressure air discharges as sprite models, Proc. 12 ${ }^{\text {th }}$ ICAE, 325-328, 2003.

Green, B. D., M. E. Fraser, W. T. Rawlins, L. Jeong, W. A. B. Blumberg, S. M. Mende, G. R. Swenson, D. L. Hampton, E. M. Wescott, and D. D. Sentman, Molecular excitation in sprites, Geophys. Res. Lett., 23, 2161-2164, 1996.

Hampton, D. L., M. J. Heavner, E. M. Wescott, and D. D. Sentman, Optical spectral characteristics of sprites, Geophys. Res. Lett., 23, 89-92, 1996.

Hardman, S., R. L. Dowden, J. Brundell, J. Bohr, Z. Kawasaki, and C. J. Roder, Sprite observation in northern territory Austrarlia, J. Geophys. Res., 105, 4689-4696, 2000.

Heavner, M. J., D. Hampton, D. D. Rentman, and E. M. Wescott, Optical Spectra of Sprites, Proc. 10th ICAE, 608-611, 1996.

Hayakawa, M., F. Yokose, Y. Ida, and D. Iudin, Multi-fractal analysis for thunderstorms leading to generation of sprites and elves, Jour. Atmos. Electr., 26, 51-57, 2006.

Lyons, W. A., Characteristics of luminous structures in the stratosphere above thunderstorms as imaged by low-light video, Geophys. Res. Lett., 21, 875-878, 1994.

Lyons, W. A., Sprite observations above the U.S. High Plains in relation to their parent thunderstorm systems, J. Geophys. Res., 101, 29,641-29,652, 1996.

Pasko, V. P., U. S. Inan, T. F. Bell, and Y. N. Taranenko, Sprites produced by quasi-electrostatic heating and ionization in the lower ionosphere, J. Geophys. Res., 102, 4529-4561, 1997.

Sentman, D. D., and E. M. Wescott, Observations of upper atmospheric optical flashes recorded from an aircraft, Geophys. Res. Lett., 20, 2857-2860, 1993.

Sentman,D.D., E.M.Wescott, D.L.Osborne, D.L.Hampton, and M.J.Heavner, Preliminary results from the Sprites 94 aircraft campaign:1. Red Sprites, Geophys. Res. Lett.,22, 1205, 1995.

Sentman, D. D., M. J. Heavner, D. J. Hampton, and E. M. Wescott, Branching Structures in Sprite Tendrils, Proc. 10th ICAE, 604-607, 1996.

Vaughan, O. H., and B. Vonnegut, Recent Observations of Lightning Discharges From the Top of a 
Thundercloud Into the Clear Air Above, J. Geophys. Res., 94, 13,179-13,182, 1989.

William, L. B., O. H. Vaughan Jr., R. J. Blakeslee, B. Vonnegut, M. Brook, and J. McKune, Observations of lightning in stratosphere, J. Geophys. Res., 100, 1465-1475, 1995.

Wescott,E.M., D.D.Sentman, D.L.Osborne, D.L.Hampton, and M.J.Heavner, Preliminary results from ther Sprites 94 aircraft campaign: 2. Blue Jets, Geophys. Res. Lett., 22, 1209, 1995.

Wescott, E. M., H. C. Stenbaek-Nielsen, D. D. Sentman, M. J. Heavner, Triangulation of sprites associated halos and their possible relation to causative lightning and micrometeors, J. Geophys. Res., 106, 10,467-10,477, 2001.

(Received December 20, 2006; revised May 2, 2007; accepted May 28, 2007) 